\title{
LOS DIÁLOGOS DE LA HABANA Y LAS PERSPECTIVAS DE UNA PAZ DURADERA EN COLOMBIA.
}

\author{
TALKS WITH HAVANA AND THE PERSPECTIVES OF A LASTING PEACE IN \\ COLOMBIA.
}

\author{
Recibido: Enero 2014 Revisado: Marzo 2014 Aceptado: 1 de Mayo 2014 \\ Por: Oto Higuita ${ }^{1}$.
}

\section{RESUMEN.}

Este artículo de investigación, presenta rutas de análisis histórico en torno a los alcances y falencias que dejaron los diálogos de Paz en Colombia entre las Frac-Ep y el Gobierno Nacional durante el siglo XX, el papel que han jugado los medios de comunicación en dichos procesos y una descripción analítica de los discursos de Oslo y la Habana, que dan inicio al actual proceso de Negociación en la Habana; se resalta el profundo alcance que este proceso de negociaciones marca en la última década en Colombia, en lo que concierne a la posible terminación del conflicto armado y la construcción de una paz estable y duradera.

\section{PALABRAS CLAVE.}

Negociación, conflicto, modelo económico, participación, paz, guerra, guerrilla.

\section{ABSTRACT.}

This research article presents routes of historical analysis over the scope and shortcomings left by the talks of peace in Colombia between FARC-EP and the National government during the twentieth century, as well as the role played by the mass media in those processes and an analytical description of the discourses in Oslo and Havana, initiating the current process of negotiations at Havana; the deep scope of this process of negotiations marks in the last decade in Colombia, is highlighted with regard to the possible termination of the armed conflict and the construction of a stable and lasting peace.

\section{KEY WORDS.}

Negotiation; Conflict; Economic Model; Participation; Peace; War, and Guerrilla Forces.

\footnotetext{
${ }^{1}$ Licenciado en Historia Económica y de las Ideas de la Universidad de Estocolmo Suecia, Estudios en inglés del University College of London (USL), escritor de artículos de opinión y ensayista en diferente medios alternativos. Activista político Marcha Patriótica Colombia, miembro de la dirección de Polo Democrático. Medellín - Colombia. Contacto: Oto.higuita@gmail.com, ohiguta@polodemocratico.com
} 


\section{Introducción.}

Este hecho histórico nos permite formularnos preguntas y hacer reflexiones de un alcance y dimensión impensables hasta hoy: ¿ ¿será posible transitar de la lucha armada a la lucha política por el poder en Colombia? ¿Qué responsabilidad les compete a cada uno de los actores armados, a la clase dominante de un lado, y a las fuerzas insurgentes por el otro, en el largo ciclo de confrontación armada? ¿Cuál ha sido el papel y responsabilidad de las instituciones estatales, partidos políticos tradicionales, de los grandes medios de comunicación, de la iglesia y los altos prelados en el largo conflicto? ¿Qué papel ha jugado el paramilitarismo, aliado del bloque dominante, en el conflicto armado? ¿Podrá la sociedad colombiana llevar a buen término los diálogos por encima de enemigos poderosos, como el que encabeza el urbibismo, Centro democrático? ¿Qué papel le corresponde a las organizaciones politicas y movimientos sociales ante el nuevo momento que se abre para la sociedad? ¿Qué posibilidad tiene la Asamblea Nacional Constituyente como mecanismo de refrendación de los acuerdos, y como proceso de empoderamiento del constituyente primario?

En efecto, la apertura oficial de los diálogos en Oslo el 18 de octubre del 2012 por la solución política del conflicto armado, abre la posibilidad a preguntas de fondo que deberian ser analizadas con detenimiento. De ser posible la lucha legal por el poder sin el recurso de las armas, ¿cómo concretar esta aspiración histórica de la mayoría del pueblo colombiano?

Pero los diálogos en sí y lo que se consiga con ellos no pueden ser entendidos como la panacea que curará todos los males. Los diálogos de paz buscan, ante todo, terminar el conflicto armado a través de una solución política. Seguramente nos gustaría que un acuerdo politico sobre el conflicto armado resolviera todos los demás problemas que tiene el país. Pero este no es el caso, ya que lo que se busca en La Habana, y seguramente en las demás mesas de diálogos con el ELN y el EPL que se establezcan, es encontrar una solución política al largo ciclo de lucha armada que hemos tenido en Colombia, y que se remonta a unos sesenta años, para ubicarnos en un punto en la historia reciente. Alcanzar esta meta histórica tiene una connotación fundamental, de ahí que no se puede minimizar su significado ante la generación actual, y menos aún, ante las futuras generaciones.

Entonces, si por medio del diálogo se logra el fin del conflicto armado y con ello una paz estable y duradera como política de Estado con la participación directa de la sociedad, y no como una proeza de un presidente, este hecho por sí solo se puede considerar como un paso trascendental para el país.

Así que lo que se acuerde en las mesas de diálogos no puede generar confusión. Los diálogos, por ejemplo, no serán la solución de los problemas históricos y estructurales que vive la sociedad colombiana. Asuntos como el modelo económico que está fundamentado en el neoliberalismo y las privatizaciones de los bienes y riquezas públicas, y que se asume no sólo como política de Estado sino que tiene legitimidad y sustento desde hace más de dos décadas en la Constitución del 91, no se discute ni se negocia en las mesas de diálogos.

Tampoco se negocia alli, los TLCs que han impactado negativamente en la vida y economía de los campesinos, y en la economía y producción agraria nacional. Y así sucesivamente una serie de problemas estructurales como la pobreza extrema 
en que siguen viviendo millones de familias; o la injusticia general e impunidad que reina en millones de casos y que se ha impuesto en el país desde instituciones como la Fiscalía, la Procuraduria, las Cortes, el Ministerio de Justicia; o como el modelo de Estado y el régimen político; ni la política extractivista de recursos y riquezas naturales; ni las relaciones internacionales y la soberanía nacional, nada de eso está en discusión ni en La Habana ni lo estarán en ninguna otra mesa de diálogos. Esto es importante aclararlo para no generar falsas expectativas, de un lado, o excesivo optimismo del otro con los acuerdos a que se llegue.

Hay una razón de fondo por la cual no se discuten ninguno de estos temas en las mesas de diálogos de paz: aunque ha habido una larga confrontación armada en Colombia, ésta no arrojó ni vencidos ni vencedores, y tampoco modificó sustancialmente las relaciones de poder. Es decir, el bloque de poder dominante, a pesar de la oposición armada y politica que se le ha hecho por décadas, sigue ejerciendo el poder hegemónicamente a través de instituciones que regulan y controlan la vida y las decisiones de la mayoría de la ciudadanía: Congreso, Cámara, Presidencia, ministerios, alcaldias, gobernaciones, Fuerzas Armadas y de policía, Fiscalia, Procuraduría, etc. Pero también a través de la educación, la iglesia y punto aparte que trataremos más abajo, a través de los medios de comunicación. Así las cosas, no tiene por qué poner en discusión su régimen y modelo de Estado, ni su modelo económico de acumulación de ganancias. ¿Por qué tendría qué hacerlo si no ha sido vencida?

No obstante lo dicho arriba, de alcanzarse un acuerdo politico definitivo sobre el conflicto armado, el conflicto social sigue vigente en tanto que hay un modelo económico y político por transformar, y es ahí donde los nuevos y viejos actores de la lucha de clases encontrarán otra vez su razón de ser. Es en el conflicto social y político, a partir de las condiciones que cree y abra los acuerdos que se firmen, se refrenden y verifiquen, donde seguirá su trámite los demás temas fundamentales que no ha resuelto el conflicto armado. Pero para ello hay que alcanzar la carta de mayoría de edad en tanto sujetos politicos para continuar la lucha por la transformación de las relaciones de poder, y con ellas, la transformación de las formas de vida, hacia una sociedad democrática, de derechos y el goce de estos para la vida digna de la mayoría de sus ciudadanos.

Y no como ha sucedido hasta ahora que una minoría en el poder ha usufructuado no sólo el poder sino las riquezas de la nación. De lo que se trata cuando hablamos de un nuevo momento, es de cambiar las condiciones de injusticia y opresión, por condiciones de justicia social y libertad. Es en este nuevo escenario, cualitativamente diferente, donde los nuevos sujetos politicos y movimientos sociales jugarán con mayor intensidad y actividad su rol, recuperando su papel histórico y su carácter amplio, popular, democrático y alternativo.

Para empezar, hay que tener en cuenta que una importante franja de la población ha estado sometida al yugo de la manipulación ideológica y mediática de la clase dominante en su empeño por defender el poder y sus intereses económicos y políticos. A lo anterior se suma un tema que tiene que ver con la forma de hacery narrarla historia en Colombia. En tanto que en este largo conflicto no hay vencedores ni vencidos, se requiere de una mirada plural y transversal sobre el conflicto, sus origenes, su historia y sus actores que tenga en cuenta las distintas visiones y enfoques sobre el mismo. Sobre esto último se ha nombrado, recientemente, la Comisión Histórica sobre las causas y origen del conflicto, lo cual es un hecho importante. 
La manipulación ideológica y mediática a que ha estado sometida una considerable franja de la población a lo largo de la historia, explica en parte por qué el desconocimiento y "supuesto" rechazo de ésta a un posible acuerdo definitivo que ponga fin al enfrentamiento armado que hemos vivido durante décadas. Sin embargo, una importante franja de opinión ha venido ganando terreno en el debate sobre la importancia de lograr una negociación política, como condición para la conquista de la justicia social.

En Colombia nunca hemos vivido una apertura democrática real donde la oposición política no fuera considerada por el bloque de poder dominante, como un enemigo al que hay que reprimir, exterminar y eliminar por la maquinaria de guerra estatal y para estatal, tal y como ha sucedido a lo largo de la historia. E1 Estatuto de Seguridad durante el gobierno de Julio César Turbay (1978-1982), el permanente Estado de Excepción y la política de Seguridad Democrática de los últimos gobiernos, así lo corroboran.

Lograr una solución política que ponga fin al largo conflicto armado ha sido hasta ahora imposible en Colombia, como lo demuestran cuatro frustrados procesos de diálogos por la solución politica y otros intentos como el de Caracas (1991) y Tlaxcala (1992), por calmar los vientos de guerra que ha vivido el país.

Durante el siglo XX hubo cuatro procesos de diálogos para la solución política del conflicto.

En 1953 el dictador Gustavo Rojas Pinilla ofreció un armisticio y amnistía general a miles de campesinos liberales y comunistas, conocidos como las guerrillas del Llano, que se habían levantado contra la persecución, expropiación de sus tierras y exterminio de manos de los terratenientes apoyados principal, pero no exclusivamente, por gobiernos conservadores, las fuerzas de policía y los aparatos armados al servicio del Estado colombiano; tendencia que se acentuó en los gobiernos de Mariano Ospina y Laureano Gómez (1946-1953).

La sociedad en su conjunto no es la responsable del fracaso de los diálogos por la solución política del largo conflicto armado. Por el contrario, el pueblo colombiano en su mayoria, ha manifestado de diferentes maneras su voluntad e interés por que cese por fin el enfrentamiento armado entre hermanos. Ante este nuevo reto que se ha abierto a partir de la mesa de diálogos de La Habana, que seguramente incluirá a otras fuerzas insurgentes, la máxima aspiración ciudadana sobre los diálogos gana cada vez mayor terreno en sectores anteriormente apáticos al proceso. Las incertidumbres que existen hoy sobre el mismo, se disipan en la medida en que avanzan los acuerdos. Es en ese sentido que debemos entender los dos discursos que inauguraron oficial y públicamente hace ya más de dos años el debate entre dos visiones politicas antagónicas en Colombia.

Contexto histórico: el siglo XIX y el primer armisticio durante las guerras de Independencia.

Las guerras civiles han jugado un papel determinante en las relaciones de poder y la permanencia de los conflictos bélicos en la historia de Colombia. Han cortado como un bisturí en lo profundo del tejido social a lo largo de la historia republicana, causado tragedias y baños de sangre que nos persiguen como fantasmas de generación tras generación. 
$\mathrm{El}$ antecedente de las guerras civiles lo encontramos en las guerras de Independencia durante las primeras décadas del siglo XIX. Sólo hasta que los ejércitos coloniales españoles probaron el polvo de la derrota ante los ejércitos patriotas comandados por los criollos revolucionarios, se firmó el primer armisticio. Pero a éste armisticio se llegó tras un espantoso baño de sangres provocado principalmente por las huestes de los “pacificadores” españoles, como Domingo Monteverde y Pablo Morillo.

El primer armisticio que conocemos de la época de las guerras de Independencia lo suscribió Simón Bolivar al frente de los ejércitos patriotas, y Pablo Morillo, el "pacificador", a nombre de los ejércitos realistas.

Durante las guerras que hicieron los ejércitos patriotas contra el dominio colonial español, fueron varias las derrotas y dificiles momentos que vivieron las primeras repúblicas. Ya en el Manifiesto de Cartagena del 15 de diciembre de 1812 (Bolivar S. , 1812) Bolivar analizó con detalle y profundidad las causas que llevaron a la destrucción y reconquista de la primera República liberada (Venezuela 1810) del dominio español. Esta derrota, llevó a la humillante capitulación de Francisco Miranda ante el jefe realista Domingo Monteverde, el 25 de julio de 1812.

A pesar de este retroceso, los ejércitos patriotas al mando de Bolivar emprendieron una rápida y exitosa campaña militar en 17 días, aplicando nuevas tácticas de guerra que inició en Barranca liberando todas las provincias del Magdalena y recuperando la comunicación entre los tres estados granadinos.

El fragor y la intensificación de la guerra por la Independencia llevó al ejército realista, comandado por Domingo Monteverde en Venezuela, a la exacerbación de la muerte, al punto que un oficial español llegó a decir sobre los americanos: La plaga que se extiende entre ellos [los patriotas] es asi extirpada, y el ejército [realista] no necesitará perder más tiempo en inspecciones. La respuesta al despiadado exterminio se dio el 15 de Julio de 1813 con el Decreto de La Guerra a Muerte proclamado por Bolivar y fijado en la plaza de Trujillo (Venezuela).

"Tocados de vuestros infortunios, no hemos podido ver con indiferencia las aflicciones que os hacian experimentar los bárbaros españoles, que os han aniquilado con la rabia y os han destruido con la muerte; que han violado los derechos sagrados de las gentes; que han infringido las capitulaciones y los tratados más solemnes; y, en fin, han cometido todos los crimenes, reduciendo la república de Venezuela a la más espantosa desolación. Así, pues, la justicia exige la vindicta, y la necesidad nos obliga a tomarla. Que desaparezcan para siempre del suelo colombiano los monstruos que lo infectan y han cubierto de sangre; que su escarmiento sea igual a la enormidad de su perfidia, para lavar de este modo la mancha de nuestra ignominia y mostrar a las naciones del universo que no se ofende impunemente a los hijos de América." Y termina el Decreto con esta insoslayable sentencia de muerte y alabanza de la vida: "Españoles y canarios, contad con la muerte, aún siendo indiferentes, si no obráis activamente en obsequio de la libertad de América. Americanos, contad con la vida, aún cuando seáis culpables”. (Bolivar S. , Decreto de Guerra a muerte. , 1813)

Ya avanzada la guerra y tras casi ocho años de enfrentamientos, empezando el año 1819, al general Pablo Morillo le llegó una orden de España que le solicitaba una conciliación fraternal con los sublevados de América, para poner fin a una guerra que agotaba la economía española. Contribuyó a ello, además, la crisis desatada 
por la insubordinación de Rafael del Riego, jefe de uno de los cuerpos del ejército expedicionario español y que terminó en una insurrección popular que llevó a que los soldados españoles se negaron a marchar hacia América. El pacificador, como se le conoce a Morillo, propició entonces un armisticio con el ejército patriota victorioso, que lo mínimo que reclamaba a cambio era el reconocimiento por parte de España de la "República Independiente, bases únicas sobre las cuales puede tratar el gobierno de Colombia con el Español," como lo pidió Bolívar en una carta a Pablo Morillo. España ofrecía "constitución y paz," Colombia exigía "paz e independencia." Así se firmó el primer armisticio durante la guerra de Independencia el 26 de noviembre de 1.820 en Santa Ana, Venezuela. (Bolivar \& Morillo, Tratado de Armisticio, 1820) La Independencia de las colonias americanas del dominio colonial español, no significó estabilidad y paz para las nuevas repúblicas que surgieron de aquellas guerras, sino la disputa del poder politico entre las facciones criollas que conquistaron poder, honor, riquezas y gloria. Entre 1824 y 1908 hubo 8 guerras civiles generales, dos internacionales y tres cuartelazos. El cambio del siglo XIX al XX (1899 - 1902) fue testigo de la Guerra de los Mil días que causó unos 180.000 muertos. En tiempos menos remotos, la crisis sistémica y del modelo político y económico colombiano, ha servido de antesala en diferentes coyunturas históricas para convocar referendos, asambleas constituyentes, plebiscitos, reformas vía congreso, así como para decretar Estados de Sitio (medidas de excepción donde las garantías constitucionales son suspendidas) como medidas de control, reforma y defensa del statu quo de grupos y sectores dominantes.

Cada que la sociedad atraviesa profundas crisis con graves connotaciones socioeconómicas y políticas, reclamando cambios democráticos en las estructuras jurídicas y politicas del Estado, el bloque de poder dominante ha recurrido a dichos instrumentos para legitimar su poder político; imponer una reforma constitucional; decretar la derogatoria de la anterior como sucedió con la constitución centralista que impuso Rafael Núñez en 1886, contra la federalista (Rionegro 1863); declarar la muerte política de la oposición; restablecer consensos en las clases dominantes para el ejercicio del poder (Frente Nacional) tal como se hizo a través del plebiscito de 1957 luego de la guerra civil conocida como la "Violencia" (1948 - 1964) desatada tras el asesinato el 9 de abril de 1948 de Jorge Eliécer Gaitán; firmar acuerdos de "paz" buscando la democratización de la sociedad (Constitución 1991); cumplir acuerdos adquiridos con el imperialismo Norteamericano tanto en el tema de la guerra "antiterrorista" a través del llamado Plan Colombia, como para cumplir los mandatos del Banco Mundial como fue el caso del referendo que convocó el presidente Álvaro Uribe en octubre del 2003; o como se hizo en el 2005, reformar la Constitución vía Congreso de la república para establecer la reelección, lo cual fue el requisito para que Alvaro Uribe continuara en el poder.

\section{Metodología.}

Se asumió la lógica del estudio histórico, analítico - hermeneutico, para lo cual se acudió en un primer momento, a un rastreo documental, contrastación de fuentes, rastreo de fuentes institucionales y no institucionales, elementos y hallazgos que fueron confrontados en un segundo momento, en varios escenarios de discusión y debate con académicos ya actores especializados en el marco de la temática aborda; lo que permitió contrastar la información, generar rutas de análisis y encontrar elementos para el planteamiento final suministrado en el presente texto que incluye un análisis de los discursos de Oslo y la Habana; todo sobre el entendido de la importancia que tiene para la sociedad y el país, estos recientes diálogos de Paz. 
El texto presenta entonces:

- El análisis y contrataciones en torno a los diálogos y negociaciones que ha vivido el país a lo largo del Siglo XX.

- Elementos de análisis de los discursos de Oslo y de la Habana que enmarcan la comprensión de la importancia y lógica del actual proceso de negociación.

- Una aparte dedicado a los medios de comunicación y su incidencia en la creación de ambientes propicios o no, para que los diálogos avancen hacia buen término.

- Unas líneas gruesas conclusivas que buscan sentar algunas rutas de lectura del actual momento que vive Colombia, como un importante hecho político, social, económico, e histórico.

\section{Resultados - discusiones.}

$\underline{\text { Los diálogos por la solución política del conflicto armado en el siglo XX. }}$

El tema de la tierra, su tenencia y usufructo, ha determinado el conflicto en Colombia. Tras la Independencia a partir de 1819, diferentes caudillos criollos que participaron de la guerra por la Independencia, establecieron sus feudos y consolidaron su poder económico y político en sus regiones de origen a través de los ejércitos que armaron para su protección. Estos ejércitos obedecieron a grandes terratenientes, hacendados y latifundistas que articulaban alianzas y relaciones de poder alrededor de la tierra. Quienes menos se beneficiaron de las guerras de Independencia, en cuanto a la propiedad de la tierra y su uso, fueron la inmensa mayoría de los campesinos pobres, los pueblos originarios y las comunidades afrodescendientes.

El siglo XX se caracterizó por el tránsito del país rural, cuya economía estaba basada en las exportaciones principalmente de café, banano y oro, al país urbano de la modernización capitalista basado en la construcción de vías y obras públicas, que daba sus primeros pasos hacia el desarrollo industrial, donde el sector textil encabezaba el proceso. A partir de estos cambios, abandonábamos la "república señorial" de la que hablaba Antonio García (García, 1977) para dar paso a la sociedad moderna e industrializada, mientras se consolidaba una clase dominante descendiente de familias de algunos patriotas y generales que lucharon en las guerras de Independencia, heredando tierras, fortunas y poder politico. Eran los años en que los Estados Unidos pagó 25 millones de dólares tras la expropiación de Panamá, lo cual significaba un superávit en las finanzas del Estado que sirvieron para superar el déficit fiscal, al mismo tiempo que el endeudamiento y los empréstitos con la banca estadounidense, principalmente, aumentan las arcas públicas al "debe" (Garcia, 1977).

Una de las crisis económicas más graves de comienzos del siglo XX se dio entre 1928 y 1933 durante los gobiernos del conservador Miguel Abadía Méndez (1926-1930), y del liberal Enrique Olaya Herrera (1930-1934) cuando el país padece una recesión seguida por la caída de la bolsa de valores en los Estados Unidos y la consiguiente crisis mundial que ésta desató. Al período de la hegemonía conservadora, luego de la Guerra de los Mil días y la pérdida de Panamá a manos de Estados Unidos, le sigue un dificil período de republicanismo estimulado por la lucha de sectores obreros, comunistas y socialistas agrupados en el PRS (Partido Socialista Revolucionario). La huelga de los obreros bananeros de Ciénaga, Magdalena, entre el 5 y 6 de diciembre de 1928 contra las oprobiosas condiciones laborales, salariales e insalubres que 
impuso la United Fruit Co., contribuyó a romper la hegemonía conservadora en el país aunque a un costo en vidas humanas que aún es objeto de discusión, pero que sin lugar a dudas marcó un quiebre en la confrontación obrero-patronal en la historia moderna del país. La respuesta del gobierno de Abadia Méndez y su ministro de guerra (Carlos Cortes Vargas) ante el reclamo de los obreros bananeros, fue ametrallar y masacrar a los trabajadores causando miles de muertos (Uribe, 2013).

La década de los años cuarenta intensificó la violencia llevándola con mayor intensidad del campo a la ciudad, tras el magnicidio de Jorge Eliécer Gaitán, el 9 de abril del 1948. Con el asesinato de Gaitán, sectores de la alta burguesía bipartidista liberal- conservadora pretendieron liquidar la esperanza de un cambio en Colombia. A 66 años de aquellos nefastos disparos, vale la pena preguntarse si realmente lo consiguieron, o si lo que lograron fue incendiar aún más la hoguera de la guerra.

La reacción del pueblo y las bases liberales gaitanistas, comunistas, socialistas, estudiantes y sindicatos al magnicidio del líder popular, desató un levantamiento violento y espontáneo conocido como el Bogotazo, que se convirtió en una insurrección armada de campesinos, principalmente liberales, que leyeron en la muerte del dirigente popular las oscuras intenciones de los sectores más conservadores, católicos y anticomunistas que encabezaron Mariano Ospina (19461950) y Laureano Gómez (1950-1951), con quien el país pasó de la dictadura civil que impuso con su visión anticomunista y corporativista, a la dictadura militar tras el golpe del general Rojas Pinilla.

Los conservadores Mariano Ospina y Laureano Gómez, no estaban solos en el propósito de eliminar a Gaitán y su proyecto de restauración moral de la república que quería el dirigente liberal. Contaron con el apoyo de oligarcas y dirigentes liberales como Carlos Lleras Restrepo, Eduardo Santos y muchos más. Entre este grupo de representantes de los partidos políticos de la oligarquía, maduró la idea del Frente Nacional, que fue un acuerdo entre las facciones liberal y conservadora en que estaba dividida la clase dominante. Acuerdo discutido inicialmente en la España franquista, de la que era seguidor incondicional el dirigente conservador Laureano Gómez.

El Frente Nacional consistió básicamente en la "pacificación" del país y en pactar la repartición el poder político de forma alterna (1958 - 1974) dejando por fuera al pueblo y la oposición. Se ha creído que la idea del Frente Nacional fue obra de los cuatro representantes de los partidos arriba citados, pero en realidad ya había sido sugerida por Alfonso López Pumarejo en 1956, en una carta dirigida a los liberales de Antioquia. (Silva Lujan, 1989)

Puesto que el poder económico estaba en manos de oligarcas, terratenientes y grandes empresarios, hacía falta completar la tarea de pacificar y estabilizar un país, en medio de una peligrosa agitación, que combinaba rasgos de guerra civil y el caos y la desinstitucionalización al que ella misma lo había precipitado por su sectarismo, odio de clase y dogmatismo católico.

\section{El primer ciclo de negociación y armisticio por la pacificación del país}

Cinco años después del magnicidio de Gaitán, con un dictador al frente del poder del Estado (Gustavo Rojas Pinilla, 1953 - 1957) y 300.000 muertos a cuestas, se 
llevó a cabo el armisticio y desmovilización de las guerrillas liberales en septiembre de 1953, con el fin de pacificar el país. A los "facinerosos o bandoleros", como se les llamó a las guerrillas de los Llanos, se les concedió una amnistía con el propósito de terminar la guerra civil, conocida como la Violencia, que se había desatado entre campesinos liberales y conservadores entre 1948 y 1958.

Rojas Pinilla era un general entrenado en la represión del levantamiento popular en Cali el 9 de abril de 1948, cuando fue comandante del ejército; y en Corea, donde estuvo ayudando al imperialismo norteamericano, a nombre de Colombia, en su nueva fase de expansión y conquista en plena guerra fría y de disputa geoestratégica entre el mundo comunista y el capitalista. Fue a este general entrenado en el anticomunismo a quien le correspondió, a nombre de la oligarquía bipartidista que había desatado la persecución y exterminio de campesinos, acordar un armisticio y amnistía luego de la desmovilización, con las guerrillas liberales que se habian levantado en armas contra gamonales, asesinos a sueldo, pájaros, chulavitas, policía y ejército que los reprimía y masacraba con el beneplácito y visto bueno de los jefes y oligarcas de los partidos liberal y conservador. Con su falso lema de Paz, Justicia y Libertad Rojas Pinilla ponia fin a uno de los ciclos de lucha armada que vivió el país. Tras la firma de armisticio y desmovilización de las guerrillas, muchos jefes guerrilleros liberales, como Guadalupe Salcedo y Hermógenes Vargas, fueron asesinados. Estrategia de exterminio y asesinato del opositor politico que se convertiría en política de Estado, en doctrina de seguridad nacional y en uno de los principales obstáculos para alcanzar la paz y la reconciliación en Colombia, ya que tras cada acuerdo de paz, desmovilizaciones guerrilleras, amnistías e indultos, los jefes de éstas y las bases desmovilizadas, eran asesinados.

A partir de 1953 se da inicio a un nuevo ciclo de confrontación armada en el paîs con el surgimiento de las guerrillas comunistas, marxistas y socialistas en la década de los 60s, como las Fuerzas Armadas Revolucionarias de Colombia (FARC - 27 de mayo de 1964), el Ejército de Liberación Nacional (ELN- 4 de julio de 1964) y el Ejército Popular de Liberación (EPL- 17 diciembre de 1967).

\section{El segundo ciclo de diálogos por la solución politica del conflicto armado.}

Con las guerrillas que nacieron en los años 60s se produce el segundo ciclo de negociaciones y diálogos por la solución política del conflicto armado, tras tres décadas de confrontación que causó miles de muertos. Ante unas guerrillas (FARC, ELN, EPL, M-19) fortalecidas a lo largo y ancho de la geografia nacional y convertidas en una amenaza y desafío al poder político y al monopolio de la fuerza del Estado, el gobierno del presidente conservador Belisario Betancur (1982 - 1986) decidió explorar de nuevo el camino del diálogo y la solución política como el medio para finalizar la confrontación armada.

En realidad, para la oligarquía colombiana se estaban presentando tres situaciones que de traslaparse podrían convertirse en un problema más grave y sin solución: de un lado, unas guerrillas fortalecidas significaban mayor amenaza, no solo en el campo, donde históricamente se había desenvuelto la guerra, sino ahora en la ciudad (guerrillas urbanas donde el M-19 fue verdaderamente innovadora y desafiante); del otro, unas condiciones sociales y politicas que venían favoreciendo el auge de éstas y los movimientos y partidos políticos de izquierda; y, finalmente el narcotráfico hacía su irrupción en la vida social, política y económica del país generando mayor crisis y confrontación. 
Habria que hacer un escrito solamente para tratar el tema del narcotráfico y su impacto en la sociedad y en el conflicto armado en Colombia, y eso está por fuera del alcance de este ensayo. Sin embargo, no podemos soslayar o minimizar el papel que desempeñó éste fenómeno social, económico, político y cultural que se extendió a todas las esferas institucionales, afectando la mentalidad y conducta de toda una generación.

El narcotráfico, en tanto actor social nuevo, dio origen a una clase emergente con formas nuevas de relacionarse, intercambiar y mediar en procesos, generando rupturas profundas en el tejido social y una mayor descomposición del orden político y cultural; ampliando y profundizando conflictos que venían de los tiempos de la colonia, que continuaron en la sociedad republicana, y que se acentúan en el siglo XX con la exclusión política, el caudillismo y el sistema bipartidista (liberalconservador) que ha concentrado el poder politico en Colombia.

Fenómenos como la corrupción, el soborno, el chantaje, la extorsión y el empleo de ejércitos privados para asegurar la vida y las nuevas propiedades y bienes adquiridos, así como la emulación de estilos de vida ostentosos, la concentración de grandes latifundios en manos de una nueva clase emergente, el consumo desmesurado, la compra de favores politicos o de curules en cargos públicos y otras, fueron formas social, cultural y politicamente aceptadas, principalmente por la clase dominante y los círculos interesados en la consecución de riquezas y en la captura del poder político. La nueva situación que surgió a partir del empoderamiento y expansión del narcotráfico, convertido en un poder paralelo unas veces, o aliado del Estado otras, aumentó la confrontación militar a niveles nunca antes vistos, reflejo de los diferentes intereses y contradicciones que vivia la sociedad. De un lado, un Estado inmerso en una crisis de legitimidad acumulada, que buscó alianzas y usó las estructuras asociadas al narcotráfico para reacomodarse y tratar de superar sus crisis.

Un Estado profundamente antidemocrático, excluyente, que ha perseguido y eliminado la oposición política, reacio a los cambios profundos para superar la grave crisis social, política y económica de la mayoría de colombianos. Del otro, unas guerrillas que crecieron y se fortalecieron a partir de la injusticia social y la exclusión política, y que representaban y enarbolaban una visión de país y un proyecto político diferentes a los de la clase dominante. Y, en tercer lugar, los intereses económicos y las aspiraciones politicas de una clase emergente proveniente del narcotráfico que había empezado a eliminar, como muestra de lo que estaban dispuestos a hacer, a quienes se opusieran a sus intereses (las guerrillas, activistas de derechos humanos, dirigentes sindicales, comunistas, intelectuales de izquierda y demócratas).

Esta situación de convulsión política, social y de violencia propició las condiciones para los acuerdos de paz del 24 de agosto de 1984 entre el M-19 (Corinto, Cauca), el EPL (Medellín) y el gobierno de Belisario Betancur; y el 28 de marzo de 1984 con las FARC (La Uribe, Meta). Una vez firmados los acuerdos por la solución política del conflicto armado, éstos no lograron pasar la prueba del tiempo debido a que tenía mayor peso en el bloque dominante la tesis de que era posible derrotar militarmente a las guerrillas. Fue lo que se conoció como los poderosos enemigos agazapados dentro del Estado y las fuerzas armadas, que denunció en su momento el Comisionado de Paz, Otto Morales Benitez. (2Orillas, 2013)

Dentro de este complejo, difícil y violento contexto (los años 80s) nacen organizaciones como la Unión Patriótica, el Frente Popular y A Luchar que 
se comprometen a impulsar una apertura democrática con el objetivo de abrir espacios de participación política y democrática. Pero esa idea chocó de frente con el poder de un Estado históricamente violento, blindado y cerrado, que además ha jugado a dos bandas: ha utilizado la violencia institucional y paraestatal para asesinar cualquier alternativa politica de oposición, y, legalmente, se ha reelegido y relegitimado continuamente en el poder.

Los acuerdos por la solución política del conflicto entre el gobierno de Belisario Betancury las guerrillas, fueron saboteados por la represión estatal que contaba con un aliado estratégico como el paramilitarismo, que irrumpe con fuerza en la década del 80, ligado al narcotráfico, aunque no exclusivamente, llevando al exterminio de la UP y las organizaciones populares que creyeron y apostaron por una apertura democrática. La toma violenta del Palacio de Justicia por un comando armado del M-19 el 6 de noviembre de 1985, y la retoma desproporcionada y violenta de las fuerzas armadas del Estado, cerró por el momento cualquier posibilidad de solución incruenta al conflicto armado. Con el asesinato del candidato presidencial de la UP, Jaime Pardo Leal en 1986, y cientos de sus activistas y simpatizantes, el país fue relanzado a una violencia politica sin precedentes que se intensificaría en las décadas siguientes.

Para este momento fue fundamental y determinante el papel del paramilitarismo en la confrontación armada, entendido como una estrategia para crear ejércitos privados al servicio de algunos sectores económicos y políticos con el apoyo de las Fuerzas Armadas, las llamadas Convivir, que venian proponiendo en regiones como Antioquia y el Magdalena Medio diferentes sectores terratenientes, dirigentes políticos regionales como el político antioqueño Alvaro Uribe Vélez, en alianza con la clase politica regional y nacional, empresarios y los narcotraficantes que caracterizamos como la nueva clase emergente.

La idea de hacer uso de fuerzas mercenarias que velaran por los intereses de la amalgama de los sectores descritos, tuvo en un comienzo un arraigo regional. Por ejemplo Antioquia, Córdoba, el Magdalena Medio, Santander, ciertas regiones del norte de Colombia, así como regiones del sur del país fueron los territorios escogidos para operar aquellas fuerzas paramilitares o para-estatales.

La expansión del paramilitarismo como fuerza contrainsurgente al servicio del bloque dominante, coincide y encaja muy bien con la expansión y el auge máximo que alcanza la nueva tendencia ideológica en la presidencia de la Seguridad Democrática de Álvaro Uribe Vélez entre el 2002 y el 2010, quien no solamente fue impuesto por la maquinaria de terror paramilitar, sino que representó una promesa electoral y política de un triunfo militar rápido contra las guerrillas. Proyecto político que además recibió impulso de la estrategia antiterrorista global que encabezó George Bush, presidente de los Estados Unidos, luego de los atentados a las Torres Gemelas en septiembre del 2001. De estos hechos a la cruzada antiterrorista global que se desató, solo había un paso y aquí en Colombia lo dio el gobierno (de dos períodos) de Uribe Vélez.

El tercer ciclo de diálogos por la solución politica del conflicto armado y la Asamblea Nacional Constituyente del 91: entre_la esperanza y la desilusión. 
La década del 90 se caracterizó por la intensificación del conflicto interno, a pesar de que en el campo internacional se daba una distensión de la guerra fría y se llegaba a un acuerdo entre las potencias que encabezaban la confrontación y amenaza de guerra mundial, los Estados Unidos (cabeza del capitalismo) y Rusia (cabeza del comunismo), donde la caída del muro de Berlín fue el hecho simbólico que marcó el final de la histórica pugna entre socialismo de estado y el modelo capitalista que posteriormente impuso la globalización neoliberal. De esta disputa capitalismo-comunismo, emerge victorioso el capitalismo y su modalidad neoliberal dando origen a teorías como las del Fin de la historia y el último hombre, del filósofo norteamericano Francis Fukuyama, (Fukuyama, 1992) donde se vaticina el fin de los conflictos sociales y la lucha de clases, asi como el futuro promisorio de una sociedad global que había alcanzado su desarrollo y su libertad basada en el sistema capitalista y el modelo político de sociedad democrática.

En Colombia fue como si al reloj de arena simplemente hubiera dado otra vuelta. Se volvió a hablar de la necesidad de alcanzar la paz arrastrando el peso de una inmensa tragedia humanitaria, como lo registran las estadísticas del Centro Nacional de la Memoria Histórica (que deja de lado muchos temas y una década mínimo por fuera de su estudio) entre 1958 y 2012, sobre el conflicto armado interno: 220.000 asesinatos, 25.000 desaparecidos/as, y 5 millones de desplazados. (Centro de Memoria Histórica, 2013)

En los años 90s el país vivió nuevamente un escalamiento de la violencia sin par, la guerra de los carteles de la droga contra el Estado lo habian debilitado y la sociedad atravesaba una crisis profunda. En un solo año, 1990, fueron asesinados tres candidatos presidenciales, lo cual mostraba el alto grado de violencia política. Entre marzo y abril fueron asesinados Bernardo Jaramillo, presidente de la Unión Patriótica, y Carlos Pizarro, dirigente del M-19; y en agosto del mismo año, Luis Carlos Galán, candidato presidencial por el Nuevo Liberalismo.

La década se inauguró con los acuerdos de paz de 1989, primero con el M-19 durante el final del gobierno de Virgilio Barco (1986 -1990), y en el gobierno de Cesar Gaviria (1990-1994) en 1990, con el Partido Revolucionario de los Trabajadores, el Manuel Quintín Lame y el EPL. Dichos acuerdos de paz coincidieron con la demanda de amplios sectores de la sociedad de convocar una Asamblea Nacional Constituyente a través de la Séptima Papeleta, finalmente votada en las elecciones de mayo del año 1990. A la crisis social y política se sumó el bombardeo de las Fuerzas Armadas contra Casa Verde, sede del Secretariado de las FARC, en la Uribe, Meta, el mismo día que son elegidos los delegados a la ANC. Es decir, el Estado propiciaba la "paz" con unas guerrillas, al mismo tiempo que le declaraba la guerra a otras.

La respuesta del gobierno liberal de César Gaviria a la propuesta de iniciar conversaciones con las guerrillas agrupadas en la Coordinadora Guerrillera Simón Bolivar, FARC, ELN y EPL, fue proponer unos diálogos rápidos con concentración de las tropas guerrilleras y un cese unilateral del fuego de parte de éstas, para a partir de allí contemplar la posibilidad de participar con delegados en la Asamblea Nacional Constituyente. Al mismo tiempo, la Casa de Nariño preparaba otro plan muy diferente.

"El domingo 9 de diciembre de 1990, cuando los ciudadanos acuden a las urnas para votar por los constituyentes, 46 aviones de combate, entre K-fir, Mirage y A-37, asi como decenas de helicópteros, por orden del Presidente Gaviria, atacan 
la sede del secretariado de las FARC en la Uribe. Mientras las bombas arrasan con el simbolo que representaba Casa Verde, Gaviria declara ante el país que quedaba 'abierto el camino para que la Constituyente sea el gran tratado de paz que reclamara la Corte Suprema de Justicia, en donde sea posible el pluralismo y la tolerancia por las ideas ajenas" (Romero, 2013).

Valga señalar que bajo este estado de cosas se convocó la Asamblea Nacional Constituyente en febrero de 1991, dando vida a la Carta constitucional que hoy nos rige. Sin embargo, al dejar por fuera las FARC, el ELN y un sector del EPL, es válido preguntarse, ¿cómo iba a ser posible que la nueva Constitución cumpliera con el mandato supremo de la paz?

La Constitución del 91, a pesar de la expectativa y esperanzas que generó, no logró, como resultado de las más de 24 contrarreformas que se le han hecho, el propósito supremo de la paz, sino un retroceso en cuanto a los derechos, libertades y justicia social, sirviendo de soporte jurídico y legal al modelo neoliberal convertido en doctrina y política económica de Estado, con sus consecuencias negativas para la vida de la gente más pobre en Colombia. Así completa las dos doctrinas que sustentan al bloque dominante: la doctrina contrainsurgente (anticomunista) que alimenta a las Fuerzas Armadas, y la doctrina económica neoliberal que alimenta las privatizaciones y los bolsillos de los ricos.

Sobre la desmovilización del M-19 y del sector mayoritario del EPL entre 1989 y 1990, es importante observar que hay varios factores que contribuyeron a ello. Unos ideológicos, otros políticos y otros de crisis internas. En el caso del M-19 una situación de crisis que lo tuvo a punto de desaparecer tras la toma del Palacio de Justicia, y su visión reformista contribuyó a su desmovilización. Y en el caso del EPL, las tendencias ideológicas disidentes del marxismo-leninismo contribuyeron no solo a su desmovilización, sino a que muchas de sus estructuras pasaran a ser parte del DAS rural y de los ejércitos paramilitares comandados por los hermanos Carlos y Fidel Castaño. De contradictores en armas del Estado a colaboradores insubordinados de su anticomunismo. Hay ejemplos excelentes que incluso hoy se expresan airadamente como sectarios anticomunistas en el Congreso.

Pero hay que ser justos y reconocer que la Constitución del 91 significó el entierro de la centenaria Constitución centralista de 1886 que impuso Rafael Núnez; que abrió las puertas a otras demandas populares como la Tutela, reconocimiento de los derechos de los pueblos originarios y afrodescendientes, y estableció un nuevo piso jurídico, social y político con avances importantes para la sociedad. Pero a pesar de estos importantes avances en materia de derechos, la situación actual demanda una nueva Asamblea Nacional Constituyente que no sólo refrende los acuerdos a que se llegue en la mesa de diálogos de La Habana y en otras, sino que recoja el clamor de cambio de las estructuras del Estado, del modelo económico, avance en las garantías para la participación de la oposición y su lucha por el poder político.

El cuarto ciclo de diálogos por la solución politica del conflicto armado: San Vicente del Caguán y la paz que frustró el Plan Colombia.

San Vicente del Caguán fue escenario del cuarto intento de diálogos por la solución política del conflicto armado en el país. Los diálogos se abrieron entre el presidente Andrés Pastrana (1998 - 2002) y las FARC-EP, llevando a la creación de una zona de desmilitarización, despeje y distensión, y de una agenda temática de 13 puntos. E1 
Caguán propició un debate nacional con implicaciones internacionales y regionales, a partir de encuentros con comunidades, sectores sociales, representantes del poder económico y militar, gobiernos y personalidades internacionales. Aunque se ha evaluado de manera poco crítica y limitada el proceso de diálogos del Caguán, las dos principales causas que llevaron a su fracaso, no reconocidas por el bloque de poder dominante como es lógico, fue, por una parte, la exigencia y respuesta militar de la guerrilla para que el Estado frenara el avance paramilitar en todo el país, que sembraría de muerte y desolación campos y ciudades. La segunda causa, y tal vez la más importante, fue la formulación y aplicación del Plan Colombia, una estrategia integral contrainsurgente que diseñó el Pentágono para la clase dominante y que buscaba fortalecer y reestructurar las Fuerzas Armadas colombianas para ponerlas a tono con el avance y poderío militar que venían desplegando las guerrillas en todo el país.

Hay que recordar que la década de finales del 90 hasta la primera del siglo XXI, las FARC desarrollaron una capacidad ofensiva que inclinó el equilibrio de poder militar en Colombia. En ese sentido el Plan Colombia fue acompañado de una política de copamiento y consolidación de las zonas que se le arrebataran a las guerrillas a través de la táctica de tierra arrasada que aplicarian en las zonas donde la presencia y poder de éstas eran determinantes. El ex presidente Andrés Pastrana mismo ha reconocido, que su objetivo no era la paz con las guerrillas, sino el fortalecimiento de las Fuerzas Armadas y la recuperación del terreno perdido ante la ofensiva sostenida y en progreso que traía la guerrilla desde la década anterior a los diálogos del Caguán. (Vanguardia Liberal, 2013); (Semana, 2012)

El paramilitarismo entendido como estrategia contrainsurgente, creció tanto que casi supera a su "jefe" natural, la oligarquía misma, que lo glorificó, apoyó y se valió de él para relegitimarse y empotrarse en el poder. Su desarrollo y crecimiento fue tal en las dos últimas décadas, que aparte de pretender Refundar al país por medio del Pacto de Santa Fe de Ralito del 2001 (Texto del acuerdo de Ralito, 2007) entre jefes paramilitares, terratenientes, empresarios, trasnacionales, sectores de las Fuerzas Armadas y más de cincuenta políticos y senadores, desarrolló una estrategia de terror despiadada que aplicó, principalmente, contra la población, produciendo un triunfo ficticio y temporal, más ideológico que real, sobre la verdadera confrontación armada.

Medios de comunicación: tergiversación y manipulación sobre el origen histórico del conflicto.

La verdad sobre las raíces históricas del conflicto no llega con el periódico de las mañanas, ni los noticieros de las tardes, ni a través de los grandes medios de comunicación como tampoco ha hecho parte fundamental de su matriz de opinión. No viene empaquetada en los editoriales, ni en las noticias, ni en los comentarios, las columnas de opinión, ni los análisis "sesudos" de politólogos y violentólogos, y menos en las campañas publicitarias a que están sometidas diariamente las mentes de la inmensa mayoría que se alimenta de la prensa oficial y comercial.

Por supuesto que hay honrosas excepciones en las visiones y narrativas de un grupo de demócratas e intelectuales, pero no logran balancear el relato histórico sobre las raíces históricas del conflicto, sus causas y los responsables. Una de éstas honrosas excepciones, la cumplen los medios de comunicación alternativos y populares que vienen rompiendo el cerco mediático que en todos los órdenes 
ha vivido la sociedad, confrontando desde la visión y praxis de los movimientos sociales y las organizaciones populares, la visión dominante y hegemónica del mundo. Porque lo que ha prevalecido, de manera determinante, es la visión y el relato que ha difundido el bloque de poder dominante a través de los medios de comunicación, que actúan como su caparazón ideológico.

Los medios de comunicación comerciales se han apropiado, sin el consentimiento del pueblo, del derecho a la información "pública" - un tema para investigar, desde cuándo y bajo qué mecanismos los medios de información comerciales, de familias particulares, grupos de accionistas, trasnacionales, se convirtieron en los mayores medios de comunicación públicos cuando en realidad son empresas privadas ejerciendo de cuarto poder al suplantar la labor de los partidos politicos históricos y de las instituciones estatales públicas y privadas, que ante la crisis sistémica del modelo de dominio capitalista se hayan en decadencia, completamente deslegitimizados y no pueden ejercer como antes su tarea de mantener el dominio, hegemonía y poder del Estado. Los medios de comunicación o medios de alienación masiva, se han convertido en los guardianes ideológicos y culturales, como lo demuestra en sus trabajos Noam Chomsky y Edward Herman, de los intereses de una clase y un sistema político que vive bajo un estado permanente de crisis. (Herman \& Shomsky, 2008)

De esta forma, la llamada opinión pública se convirtió en un campo de batalla de ideas donde, aunque siguen gozando de buena salud las de las clases dominantes, vienen siendo confrontadas por el campo de las ideas democráticas y de izquierda a lo largo de la historia, a partir de la profundización de la crisis del sistema capitalista en general y el avance de las tecnologías de la comunicación. Las redes sociales son también un campo de batalla donde cada segundo, la visión del bloque de poder dominante es confrontada por la visión del bloque de poder alternativo y popular que crece cada dia y se expande por todas partes.

Una evidencia de lo que afirmamos sobre el dominio de los grandes medios de comunicación, es que la opinión, análisis y propuestas de quienes ejercen oposición politica al sistema ha sido obligada a vivir permanentemente bajo la autocensura que impone la amenaza de muerte, o el exilio por la misma razón, o la cárcel por un montaje judicial o la tumba como ha sucedido con miles de activistas de movimientos progresistas, de izquierda o comunistas, o con decenas de intelectuales, artistas, periodistas, reporteros, humoristas, profesores, estudiantes, sindicalistas, obreros, indigenas, afro descendientes, disidentes sexuales, convirtiendo a Colombia en uno de los países más ricos en cementerios clandestinos donde yacen miles de desaparecidos, testigos olvidados, que fueron callados para siempre por una politica criminal que se ha practicado desde el poder del Estado.

Se ha acallado y censurado a tal extremo las posturas politicas de la oposición democrática, popular, de izquierda y comunista, al punto que el anticomunismo se convirtió en doctrina de Estado, y en la mente de una mayoría de la opinión pública colombiana parece (es la mentalidad o consenso que ha construido la derecha y la clase dominante desde sus medios de comunicación, la radio, la TV) que no existe nada distinto al modelo único de sociedad capitalista, algo así como un estado natural de la sociedad, eterno, duradero e inmodificable. De esta forma, muchos opositores de izquierda y demócratas han sido obligados a la autocensura, a ese perturbador silencio autoimpuesto que lo mantiene entre la disyuntiva de ser asesinado y vivir 
entre las fronteras de la conspiración o la militancia armada para hacer valer su palabra, así ésta sea la forma más extrema de existencia como sujeto político.

A partir de estos planteamientos, es válido preguntarnos entonces, ¿qué espacio para la difusión de ideas ha tenido la oposición política en este país, cómo ha sido tratada por los grandes medios de comunicación? Lo que la oposición diga, convoque o proponga es dificilmente presentado con seriedad y rigurosidad por dichos medios, por el contrario, es atacado y por lo general vilipendiado, tergiversado o caricaturizado.

Pero sin duda, el más grave ataque que se le ha hecho a la oposición, es señalarla de aliada o cómplice de la guerrilla con todas las consecuencias que este tipo de estigmatización ha significado para los sectores democráticos, progresistas y de izquierda. ¿Hay una lógica en esto? Cuando el verdadero poder político y económico ejerce su poder e influencia sobre los medios de comunicación, les impone la defensa de sus privilegios, del modelo social vigente, la censura, la exclusión y hasta el control militar, podemos entender las lógicas y mecanismos de funcionamiento de los medios de comunicación.

De ahí que la comunicación, información, noticias, análisis, entretenimiento y publicidad que divulgan a una velocidad virtual, impensable hace dos décadas, los medios de comunicación comerciales a través de la tecnología de la comunicación, no puede ser catalogada como fuente veraz, imparcial y objetiva por el hecho de que quienes la producen y divulgan, los comunicadores y empleados asalariados de dichos medios, por convicción o necesidad están condicionados y, en la mayoría de los casos, se ven obligados a difundir la visión y objetivos de los propietarios de los grandes medios de comunicación.

La sociedad colombiana se debe un debate serio y profundo sobre cuál ha sido el papel de los grandes medios de comunicación en una sociedad caracterizada por un conflicto social y armado con raíces y causas históricas, y hoy en medio de los diálogos por la solución política del mismo, se hace más urgente y necesario propiciarlo. Cuál debe ser su papel en una sociedad libre de conflicto armado, democrática y de derechos, es una pregunta que reclama respuesta con urgencia.

Algunos de los casos más simbólicos donde el papel de los medios de comunicación queda en evidencia en su labor de defensores del bloque de poder dominante, cuando deciden intencionalmente tergiversar falsear la verdad y los hechos, manipular la opinión pública en su papel de formadores de opinión. Como se verá el desequilibrio informativo es abismal y la tergiversación de la verdad y la historia lo evidente. La mujer del collar bomba

El caso de la mujer collar-bomba (E1 tiempo, 2002) ejemplifica nítidamente cómo se construye una imagen distorsionada de los hechos para que produzca un efecto impactante sobre una gran franja de la población que consume "noticias". Los medios de comunicación se propusieron al unísono producir en el imaginario colectivo la idea de que las FARC cometieron el crimen. Este es uno de los casos más emblemáticos por lo trágico y doloroso, donde los grandes medios al servicio del poder usando como fuentes únicas a las Fuerzas Armadas y con una clara orientación ideológica y política, cometieron conscientemente una grave falsificación y tergiversación de la realidad. 
El 17 de mayo del 2000 Colombia y el mundo conocieron la barbarie y crueldad de la guerrilla de las FARC, que anunciaban a cuatro vientos los titulares de los medios de comunicación nacionales e internacionales, donde se le acusaba de colocarle a una campesina un collar cargado de explosivos para exigirle dinero. (E1 Tiempo, 2000); (Conmocion en Colombia, 2000) "Repudio en Colombia por muerte de mujer con 'collar Bomba' de las FARC, decía Caracol. Esto fue lo que dijo el diario argentino, La Nación: Elvia Cortez, una campesina que subsistía vendiendo sus cosechas en la plaza del mercado, dedicó las últimas siete horas de su vida a rezar y a pensar en su esposo y sus hijos, antes de que estallara el 'collar de explosivos' que le colocaron guerrilleros de las Fuerzas Armadas Revolucionarias de Colombia (FARC). (El Tiempo, 2000) Con esos titulares difundieron por el mundo su imagen con el collar de explosivos colocado por los terroristas de las FARC.

Dos años después tras la investigación que hizo la fiscalía, se conocieron las pruebas y se reveló que no fueron las FARC. Sin embargo, en El Tiempo se afirmaba que el juez de la república (con minúscula para no seguir abusándola) que juzgó el caso, determinó que aunque en la acción criminal no estuvieron involucradas las Farc, como lo aseguraron las autoridades inicialmente, los delincuentes tuvieron asesoria extranjera, incluso del grupo terrorista ETA, de España. (El tiempo, 2002)

La marcha del 4 de febrero del 2008 contra las FARC

El 31 de enero El Tiempo publicó un artículo titulado: La marcha del 4 de febrero contra las FARC nació como un foro en internet y ya está en 163 ciudades. (E1 Tiempo, 2008) Así empezaban el redoblar de los tambores publicitarios de la gran prensa colombiana para demostrar que el pueblo odiaba a las FARC y que las rechazaba. "Esperamos que mucha gente se concentre en las ciudades propuestas, que salgamos a la calle. Es una de las maneras para mostrar la indignación que deja un tema tan atroz como el secuestro", decía en el diario de circulación nacional la directora de País Libre, Olga Lucía Gómez. (El Tiempo, 2008)

Este es otro ejemplo de manipulación mediática extrema. Esta vez se unieron todos las instituciones estatales alrededor de una convocatoria que realizó un grupo de jóvenes por internet (que fue la excusa ideal de los medios de comunicación para agrandarla y darle eco nacional y mundial), de marchar contra el uso del secuestro cometido por las FARC.

El objetivo era bien claro, por una lado hacer una campaña sucia en su contra, y por el otro, restarle importancia e invisibilizar las graves violaciones de derechos humanos cometidas a lo largo del conflicto por el Estado y sus aliados, los paramilitares, como las miles de masacres contra la población indefensa, el desplazamientos forzado de comunidades, los miles de casos de desaparecidos, los asesinatos selectivos de líderes de oposición, el encarcelamiento masivo de dirigentes de izquierda, defensores de Derechos Humanos, sindicalistas, estudiantes, etc.

La marcha, convocada para repudiar el secuestro y el maltrato a que eran sometidos quienes se encontraban en poder de la guerrilla, terminó convirtiéndose en una campaña a favor del gobierno de Álvaro Uribe y su politica de mano dura y Seguridad democrática. Las movilizaciones realizadas el lunes 4 de febrero de 2008 contaban con el apoyo del gobierno colombiano del presidente Álvaro Uribe, los medios de comunicación, asi como de diferentes personalidades públicas, como la recién liberada Clara Rojas, miembros de la oposición y de algunos voceros de las autodefensas. (Wikipedia, 2008) 
Los convocantes a la marcha con el apoyo de los grandes medios, que hicieron de caja de resonancia, y del aparato estatal tenían como propósito señalar a las FARC de organización terrorista y se ser el principal problema del país. Con esta jugada política-mediática el gobierno de Álvaro Uribe, le restaba importancia y apoyo a la denuncia de millones de víctimas, quienes hace décadas vienen reclamando justicia, verdad, reparación y no repetición por los crímenes de Estado. Las organizaciones de víctimas de crímenes de Estado, habían anunciado una marcha con antelación a la del 4 de febrero, ante lo cual el asesor presidencial, José Obdulio Gaviria, afirmó: "Yo personalmente no participaré tal como lo hice y con todo entusiasmo en la marcha programada contra las Farc", y agregó que, "dificilmente la sociedad colombiana participará en tal tipo de convocatoria cuando precisamente estamos marchando contra los que convocan". (Caracol Radio, 2008)

A la convocatoria de marchar contra las FARC hecha a través de facebook por un grupo de jóvenes se unió, desde su matriz de opinión, el aparato gubernamental con toda su artillería mediática, los partidos políticos, los grandes tribunos del púlpito católico, la empresa pública y privada, en una sola palabra, la derecha y el establecimiento aprovechó la magnífica oportunidad para poner a marchar millones de colombianos contra las FARC. Asuntos fundamentales que tienen que ver con las condiciones de vidas de los ciudadanos de a pie quedaron relegadas a un último plano: el desempleo rampante, los salarios de miseria, la masiva informalidad en que viven millones, la corrupción, la grave crisis del sistema de salud, el alto costo de la gasolina, el alto costo de vida, el desplazamiento de millones de campesinos a quienes les fueron arrebatadas sus pequeñas parcelas, la violencia institucional, las masacres cometidas por el paramilitarismo, la violencia en las calles de las ciudades, etc.

La inmensa mayoría que salió a marchar contra uno de los actores del conflicto, las guerrillas, fue utilizada por el principal originador de violencia en el país: el Estado acompañado de los que saben crear opinión y verdad, los grandes medios de comunicación. Algunos de los familiares de secuestrados se negaron a marchar, afirmando que, "Nuestro tema es la libertad de nuestros familiares secuestrados. Nosotros nunca marcharemos ni contra las Farc, ni contra el presidente Uribe, ni contra nadie”. (E1 Tiempo, 2008).

¿Cómo logró entonces el Estado y sus instituciones convencer a millones de marchar contra uno de los actores del conflicto? Canalizando una campaña de propaganda negra contra las FARC a través de los medios de comunicación, y convirtiendo el secuestro en el crimen más atroz que se cometía en el país, por encima de los desaparecidos, torturados, asesinados y desplazados que ya existían por miles y por millones. Y alli es donde reside el contenido de clase de la propaganda oficial y de los medios de comunicación masiva. ¿A qué sector pertenecían los secuestrados? Principalmente a las clases pudientes, a las clases altas. Terratenientes, hacendados, ganaderos, empresarios, banqueros, etc. ¿Quiénes eran los asesinados en masacres, desapariciones, los falsos positivos, los torturados y los desplazados y expropiados de sus tierras? Las clases bajas y populares, pequeños y medianos campesinos, comunidades indigenas, afrodescendientes, sindicalistas, defensores de derechos humanos, intelectuales de clase media o popular, etc.

La vida de lujos y banquetes de los comandantes de la guerrilla protegidos por gobiernos vecinos. 
Otra de las grandes falsedades mediáticas convertida en propaganda de guerra, es la repetida tesis de que la comandancia de la guerrilla lleva una vida de lujo fuera del país protegida por gobiernos vecinos y que desde alli dirigen sus tropas. Campaña repetida al unísono por los altos mandos militares, los grandes medios de comunicación, intelectuales, políticos, artistas de la farándula, ministros, etc. Propaganda de guerra que hace parte de una estrategia mediática e ideológica cuyo objetivo es mostrarlas ante el país y la llamada opinión pública como un grupo de ricos mafiosos, viviendo en medio del derroche, las bacanales y el lujo.

¿Qué explica entonces que los principales líderes guerrilleros hayan caído en bombardeos o fusilados luego de un cerco militar, dentro del país? ¿Dónde fueron abatidos Martín Caballero (fusilado luego de rendición) (Farc-Ep, 2000), el negro Acacio, Raúl Reyes, el Mono Jojoy y Alfonso Cano, dónde le cortaron la mano a Iván Ríos? ¿En palacetes y bacanales como sugiere la propaganda de los medios, los militares y el establecimiento? Murieron con sus tropas, en campamentos, en una selva, o en el caso de Iván Ríos asesinado por un traidor convencido que se haría rico. $\mathrm{Ni}$ al arrogante ministro de defensa de aquella época y ambivalente presidente de hoy, Juan Manuel Santos, ni a su jefe de entonces, Álvaro Uribe, les importó violar la soberanía de un país vecino como Ecuador y poner en peligro la seguridad de la región, ya que lo que buscaban era un objetivo de alto valor eliminando al comandante de las FARC, Raúl Reyes. (El Pais, 2008)

Los discursos de Oslo y las dos diferentes miradas sobre el conflicto y la realidad del país.

Los discursos de Oslo de octubre del 2012 que pronunciaron Humberto de la Calle Lombana a nombre del gobierno, e Iván Márquez a nombre de las FARC, (Zambrano, 2012) abrieron de nuevo el viejo debate aplazado durante una década sobre la necesidad de alcanzar un acuerdo político para el fin del conflicto social y armado que vive la sociedad colombiana desde hace más de seis décadas. Sin embargo, los diálogos que cumplen ya dos años tienen un significado profundo porque implican el re-nacimiento de la politica, en el sentido de volver al debate de ideas como el método más idóneo de resolver las contradicciones en una sociedad democrática, lo cual tendrían, de prosperar, implicaciones incalculables.

El discurso leido por Humberto de la Calle Lombana a nombre del gobierno.

El discurso del vocero del gobierno tuvo un carácter ceñido al formato diplomático y con un estilo más pragmático que el del vocero de las FARC, donde se resaltó lo avanzado hasta ese día.

En su discurso, Humberto de la Calle Lombana sostuvo que, "de lo que se trata es de convenir una agenda para la terminación del conflicto que permita a las Farc exponer sus ideas sin el acompañamiento de las armas, y con plenas garantias para su transformación en una fuerza politica desarmada..." enfatizando así la importancia de los diálogos que se abren para buscarle un final a la confrontación armada y entrar en la fase (3) de la lucha política sin el recurso de las armas. "No pretendemos que las Farc no expresen sus ideas," manifestó.

Un aspecto central del discurso gubernamental, son las tres fases del proceso: la primera ya se cumplió y fue el encuentro exploratorio con la ayuda de varios gobiernos que llevó a la firma del Acuerdo General, donde se establecieron las condiciones necesarias para la terminación del conflicto. La segunda, el inicio de los 
diálogos de Oslo, para llegar a acuerdos sobre los puntos de la agenda contenidos en el Acuerdo General. Y la tercera, comenzaría con la firma del Acuerdo Final, que marcaría el fin del conflicto armado.

Sin embargo, afirmó, "Hay un punto en el que coincidimos con las Farc: la finalización del conflicto no es en sí misma la consecución inmediata de la paz. La Fase 3 es el escenario para las transformaciones necesarias que serán el verdadero motor de la paz." A partir de ahí, seguiría la implementación de lo acordado y su verificación. Reconocen que las FARC tienen una concepción del mundo y la política y no se pretende desde el gobierno que ésta guerrilla deponga sus ideas, sino las armas, y siempre y cuando sigan su lucha política en democracia.

Sobre el papel que cumpliría la opinión pública, es de importancia central no solo para el gobierno sino para el logro del propósito mismo de los diálogos, que es la finalización de la confrontación armada, para darle paso a la lucha de ideas: se afirma que hay apoyo al proceso de diálogos pero se insiste en la necesidad de que al final de la fase dos haya signos positivos de que los diálogos van por buen camino.

Respecto a este tema, crucial para la refrendación y apoyo al proceso que se inicia, se afirma además lo siguiente: la opinión pública "no es construida por el gobierno, ni manipulada", pues a partir de la Constitución del 91 hay más ciudadanía pensante que apoya las conversaciones, pero que no está dispuesta a soportar dilaciones ni trucos. ¿Quiere esto decir que la opinión pública en Colombia no es manipulada, ni la forman los formadores de opinión desde los llamados medios de comunicación comerciales? ¿O que la postura política e ideológica de la llamada opinión pública no se construye alrededor de los intereses de clase de quienes gobiernan? ¿Qué quiere decir que la opinión pública no está dispuesta a soportar dilaciones ni trucos? Es dificil creerle al vocero del gobierno en este punto, como ya hemos demostrado arriba con ejemplos claros, la manipulación mediática y la tergiversación de la realidad al servicio de las clases dominantes, es un hecho consumado en la historia de la lucha por el poder en Colombia. Lo que está en juego hoy es no solo el proceso y sus objetivos, sino la continuidad del bloque de poder por un largo ciclo más de dominio y control del aparato de Estado.

En el discurso, de La Calle Lombaba habla también de la importancia de la participación política y la necesidad de "garantizar la vida y la libertad de expresión de quienes decidan ingresar a la vida politica." Este, sin duda, ha sido uno de los obstáculos más grandes que han tenido históricamente los procesos de diálogos y solución política del conflicto.

En cuanto a la participación de sectores sociales y políticos representantes de distintas expresiones de la sociedad, plantea que "no se trabajará de espaldas al pais," sino que habrá participación "en función y de acuerdo con las necesidades de la Mesa," de diálogo.

Acerca de la agenda de discusión dice que la idea es "llegar a acuerdos sobre cinco puntos que se puedan cumplir y que buscan soluciones concretas para los temas críticos del conflicto: el desarrollo rural, las garantias para la oposición y la participación politica, el fin del conflicto, el narcotráfico y las víctimas." 
Finalmente, un punto que se repite en el discurso gubernamental es que "la terminación del conflicto armado es la antesala de la paz" y que para lograrla hay que "ir a fondo en la transformación de la sociedad." "Estamos dispuestos," recuerda de la Calle Lombana, "a buscar mecanismos de garantia que llenen estas aspiraciones."

El discurso leído por el representante oficial en la mesa de diálogos por la Paz en Oslo, no causó mayores sorpresas ni grandes expectativas porque fue un resumen de lo que hasta ese día se había avanzado en el proceso, y porque además no es la primera vez que el gobierno habla en un foro sobre la paz, ni tampoco por que haya tenido la boca callada en los últimos 50 años, por el contrario ha tenido la palabra y la voz desde los tiempos en que la oligarquía hegemonizó el poder para su uso y ejercicio exclusivo.

\section{El discurso leido por Iván Márquez.}

El discurso del vocero de las FARC sí generó malestar y discordia. Una década de censura, acusaciones de terroristas, narcotraficantes y guerreristas les ofrecía una buena ocasión para volver a expresar sus ideas, análisis y propuestas ¿En resumidas cuentas, qué fue lo que dijo?

En primer lugar, fue un discurso más largo que el del gobierno donde las FARC expresan las razones históricas que las llevaron a la lucha armada, las mismas por las que se mantendrian en lucha de no cambiar las condiciones que las llevaron a la lucha armada. Pero el documento leído por Iván Márquez es ante todo la palabra, la voz y las motivaciones de una lucha que se pretendió desconocer y negar por más de una década, desde que el gobierno de Andrés Pastrana finalizara los diálogos del Caguán en el 2002, una vez la maquinaria de guerra y el Plan Colombia rediseñaron una nueva fase de la guerra que, en palabras del gobierno de la Seguridad Democrática que estuvo en el poder dos períodos (2002 - 2010), acabaria en unos meses con la guerrilla.

Segundo, el discurso de las FARC es un mapeo actualizado de los conflictos y luchas de las comunidades a lo ancho y largo de la geografia nacional donde se señala con nombres propios los protagonistas de dichos conflictos. No hay nada nuevo en ello como bien han señalado muchos analistas políticos.

¿Entonces, en quiénes generó rechazo el discurso de Iván Márquez? Principalmente en el sector del bloque dominante convencido de que la guerra es la única solución a los problemas del país; en los formadores de opinión de los medios de comunicación comerciales que tienen de antemano construida una imagen del conflicto y de la guerrilla; en los voceros de las trasnacionales y sus aliados capitalistas rentistas; y obviamente en la derecha agrupada en los latifundistas, los ganaderos que monopolizan casi 40 millones de hectáreas de tierra, y en un sector emergente ligado al narcotráfico y la política, parapolíticos, que se conformó como resultado de las alianzas entre ejércitos paramilitares y narcotraficantes en las guerras de las últimas décadas.

El discurso de Iván Márquez empieza afirmando, "Venimos a esta Noruega septentrional a buscar la paz con justicia social para Colombia por medio del diálogo, donde el soberano, que es el pueblo, tendrá que ser el protagonista principal. En él reposa la fuerza irresistible de la paz. Ésta no depende de un acuerdo entre voceros de las partes contendientes. Quien debe trazar la ruta de la solución politica es el pueblo 
y a él mismo le corresponderá establecer los mecanismos que han de refrendar sus aspiraciones." "...una paz que no aborde la solución de los problemas económicos, politicos y sociales generadores del conflicto, es una veleidad y equivaldria a sembrar de quimeras el suelo de Colombia."

Venimos a los diálogos de Oslo, continúa "por una paz que implique una profunda desmilitarización del Estado y reformas socioeconómicas radicales que funden la democracia, la justicia y la libertad verdaderas."

Luego aborda uno de los temas que dieron origen a la lucha armada en el país, el problema agrario. "En nuestra visión, colocar sobre la mesa el asunto del desarrollo agrario integral como primer punto del acuerdo general remite a asumir el análisis de uno de los aspectos centrales del conflicto. El problema de la tierra es causa histórica de la confrontación de clases en Colombia."

Cómo entienden las FARC el problema de la tierra? "Para las FARC, el concepto TIERRA está indisolublemente ligado al territorio; son un todo indivisible que va más allá del aspecto meramente agrario y que toca intereses estratégicos, vitales, de toda la nación. Por eso la lucha por el territorio está en el centro de las luchas que se libran hoy en Colombia. Hablar de tierra significa para nosotros hablar del territorio como una categoría que además del subsuelo y el sobresuelo entraña relaciones sociohistóricas de nuestras comunidades que llevan inmerso el sentimiento de patria, que concibe la tierra como abrigo, y el sentido del buen vivir. "

Sobre la titulación de tierras que adelanta el gobierno, las FARC hacen una denuncia al afirmar que, "la titulación de tierras, tal como la ha diseñado el actual gobierno, es una trampa; encarna una suerte de despojo legal a través del cual se busca que el campesino, una vez con el título de propiedad en sus manos, no tenga otra salida que la de vender o arrendar a las trasnacionales y conglomerados financieros, a los que sólo les interesa el saqueo exacerbado de los recursos minero-energéticos que están debajo del suelo. Dentro de su estrategia está la utilización del suelo para extender las explotaciones forestales y las inmensas plantaciones, no para resolver el grave problema alimentario que padece nuestro pueblo, sino para producir agrocombustibles que alimentarán automóviles. En el mejor de los casos, la gente del campo quedará con una renta miserable, pero alejada del terruño y confinada en los cinturones de miseria de las grandes ciudades. Al cabo de 20 o 30 años de contrato nadie se acordará del verdadero dueño de la tierra. Lo aseguramos sin vacilación: la bancarización de la tierra derivada de la titulación, acabará 'tumbándole' la tierra al campesino. Nos están empujando a la extranjerización de la tierra y al desastre ambiental dinamizado brutalmente por la explotación minero-energética y forestal. La naturaleza como fuente de información genética no puede ser convertida en botín de las trasnacionales. Nos oponemos a la invasión de las semillas transgénicas y a la privatización y destrucción de nuestra biodiversidad y a la pretensión de hacer de nuestros campesinos pieza del engranaje de los agro-negocios y sus cadenas agroindustriales. Están en juego la soberanía y la vida misma."

Sobre este tema, un informe sobre desarrollo humano del Programa de las Naciones Unidas para el Desarrollo del 2011 afirma que, uno de los problemas más grandes que enfrentan los campesinos colombianos es precisamente la casi nula distribución de la riqueza y de la tierra. Alli se indica que el 52 por ciento de la gran propiedad está en manos del 1,15 por ciento de la población. La 'ganaderización' de la tierra en Colombia, se soporta en la nada despreciable realidad de que, 39,2 millones de 
hectáreas están destinadas para pastos, rastrojos y malezas, de las cuales 31,6 millones están usadas en ganadería bovina, donde hay menos de una cabeza de ganado por hectárea. (Pnud, 2011)

Sostiene, además, que el despojo de tierras en el país está en 6,6 millones de hectáreas, de las cuales se han recuperado 495.493. De ese total, el 73 por ciento corresponde a minifundios y propiedades pequeñas de hasta 20 hectáreas. En los últimos 13 años, concluye, unos 3,6 millones de personas han sufrido el desplazamiento forzoso, de las cuales el 65 por ciento son menores de 25 años y el 14 por ciento menores de 4.

Ya en el 2006 el Centro de Investigaciones para el Desarrollo (CID), de la Universidad Nacional de Colombia había presentado un adelanto sobre el tema en un informe que no dista mucho del anterior. En éste, aparte de calificar el crecimiento de la economía colombiana durante el primer gobierno de Álvaro Uribe $(2.002-2.006)$ de inequitativo, insuficiente, concentrado e insostenible, se afirmaba que Colombia era el país con la más inequitativas distribución de la tierra del continente. Un $68.2 \%$ de la población campesina padecia una situación de pobreza grave. Solo una minoria, 2.428 propietarios, poseían 44 millones de hectáreas, equivalentes al $53.5 \%$ del territorio. Los 2.3 millones de campesinos que solo poseían tierras o predios de menos de 3 hectáreas, o sea el 1.7\% del territorio, no cuentan sino como mano de obra barata. Sumado a lo anterior, la mayoria de propietarios $(55.6 \%)$ y de predios $(56.8 \%)$ poseian tierras menores de 3 hectáreas. Es decir, eran dueños del $1.7 \%$ del territorio registrado catastralmente. Mientras, 2.428 grandes propietarios poseen 44 millones de hectáreas, que equivalen al 53.5\% del territorio. Siendo dueños de 18.093 hectáreas por propietario, o un territorio 6.000 veces más grande que el minifundio de 3 hectáreas al que aspiraban 2.3 millones de colombianos. (Centro de investigacion para el Desarrollo, 2006)

En particular las FARC, sostiene su delegado, consideran que "la titulación no es más que la legalidad que pretende lavar el rostro ensangrentado del despojo que durante décadas ha venido ejecutando el terrorismo de Estado." Sin embargo, para mucha gente que no analizó detenidamente el discurso de las FARC, bien porque no les interesa o porque no comparten lo que se dice allí, es válido señalar que en éste no solo hay un rechazo y denuncia de la titulación de tierras. A renglón seguido afirman que "no se oponen a una verdadera restitución y titulación de tierras. Por años hemos luchado, como pueblo en armas, por una reforma agraria eficaz y transparente, y es precisamente por ello que no se puede permitir que se implemente el despojo legal que el gobierno proyecta con su ley de tierras."

Al respecto habria que señalar que hoy el debate va más allá de la mera devolución de títulos de propiedad a los millones de campesinos expropiados y expulsados de sus territorios, o la mera reforma agraria como se concibió en los años sesentas y setentas. Hoy existe una visión integral del conjunto de factores ligados al problema agrario como el ambiental, la explotación minero energética y uso del suelo y subsuelo y sus consecuencias que viene siendo motivo de fuertes luchas y preocupación de las comunidades, la soberanía alimentaria, la relación territoriohistoria-cultura de los pueblos, etc. En este sentido la discusión del problema de la tierra atañe al conjunto de la sociedad, donde la soberania nacional, a pesar de los cantos de sirena de la globalización a favor de las multinacionales y las grandes potencias capitalistas, adquiere una importancia central. 
La parte final del discurso de las FARC insisten en que se identifican con el "clamor mayoritario de la nación por encontrarle una salida dialogada al conflicto abriendo espacios para la plena participación ciudadana en los debates y decisiones." Pero que éste propósito superior de Paz no puede confundirse simplemente con el silencio de los fusiles, sino que implica transformaciones en la estructura del Estado, las formas políticas y militares. "La paz no es la simple desmovilización."

Así mismo señalan el peligro que puede correr este nuevo intento de Paz si se coloca como espada de Damocles, a pender amenazas sobre la existencia de esta mesa. Y llaman a someter las razones de cada una de las partes contendientes al veredicto de la nación, a la veeduría ciudadana.

La cuestión del papel de los medios de comunicación privados la plantean en términos de no permitir que "los manipuladores de opinión, desvien el rumbo de esta causa necesaria que es la reconciliación y la paz de los colombianos en condiciones de justicia y dignidad. La gran prensa no puede seguir actuando como juez inicuo frente al conflicto."

\section{Conclusiones}

En los dos años desde que se instauró la mesa de La Habana, ha corrido mucha agua bajo el puente. Innumerables peligros y amenazas han tenido que ser sorteados; la confrontación militar sigue causando víctimas de lado y lado incluyendo a la población civil; se han hecho grandes movilizaciones de carácter local, regional y nacional mostrando el apoyo y respaldo a los diálogos de La Habana, como la movilización por la paz con justicia social del 9 de abril del 2013; 2014 fue un año electoral donde el pueblo mayoritariamente eligió el mandato por la paz y el apoyo a los diálogos, reeligiendo a Juan Manuel Santos y donde la izquierda y los sectores democráticos se movilizaron desde diferentes escenarios y plataformas como los Frentes Amplios para apoyar y defender el proceso de diálogos y la paz con justicia social; el llamado a establecer otra mesa con las dos organizaciones insurgentes que están reclamando un diálogo; infiltraciones y saboteo a las delegaciones de paz de La Habana; las vacilaciones y ambigüedades del gobierno de Santos respecto al proceso y a mantener un ministro de guerra que cumplió ya su ciclo y sigue tratando de sabotear los diálogos; la intención del gobierno de firmar una "paz express" reclamando la desmovilización y entrega de armas cuando no está contemplado en los 5 puntos de la agenda; la represión, encarcelamiento, asesinatos y estigmatización contra los movimientos sociales y populares que protestan y reclaman derechos como en el caso del paro nacional agrario del 2013.

Cuando fueron leídos los discursos de apertura para la terminación del conflicto armado y la construcción de una paz estable y duradera en Oslo, una nota monótona de rechazo recorrió como una onda expansiva la sociedad colombiana: era la algarabía rabiosa de los medios de comunicación. Nota coordinada y difundida por los formadores de opinión de los grandes medios que esperaban "escuchar" en el discurso leído por Iván Márquez la claudicación de la guerrilla y no un mapeo político e histórico detallado del conflicto social y armado. Tal vez a muchos los tomó por "sorpresa" que las FARC tengan un análisis no solo actualizado de la realidad del país, sus conflictos, contradicciones y propuestas de solución, sino que incluso hayan profundizado en asuntos tan trascendentales como el tema agrario. Esa actitud es entendible cuando desde dichos sectores del poder y los grandes medios de comunicación, se insiste en ver las cosas unilateralmente a través del prisma de 
sus propios intereses. Un modo particularmente construido desde las editoriales, opinión y estrategia publicitaria del sistema.

Los medios de comunicación son, sin duda, responsables de lo que ha sucedido en el país, del conflicto social y armado, son cómplices de los responsables históricos de la violencia, de la imposición de un modelo económico que ha enriquecido a unos pocos y mantenido en la pobreza a millones, y de cubrir la mala imagen de un régimen político corrupto y deslegitimizado porque son orgánicos al poder.

No podrán esquivar más preguntas como: ¿Desde cuándo viene el Estado cometiendo sistemáticamente, violaciones contra sectores del pueblo? ¿Desde hace 50 años con el surgimiento de las guerrillas? ¿O antes de que ellas surgieran, unas décadas atrás? ¿Cuándo, por qué y por quiénes, se desató la violencia en Colombia?

Hay muchos ejemplos de cómo los grandes medios de comunicación continúan manipulando la mentalidad de la gente, con el objetivo de generar un consenso político en la ciudadanía a favor de los intereses del bloque de poder dominante. Y es aquí donde los medios de comunicación alternativos y populares vienen cumpliendo una labor trascendental en estos nuevos tiempos, desde la socialización y difusión de noticias e información que en general pasa desapercibida por los grandes medios de comunicación comerciales, en el debate de ideas, así como en la creación de materiales audiovisuales y en el acompañamiento, cubrimiento y visibilización de las luchas, pliegos y demandas de las comunidades en resistencia.

Si como vaticinó Marx en el Manifiesto Comunista, toda la historia de la sociedad humana, hasta el dia, es una historia de luchas de clases, la batalla de ideas es uno de los escenarios principales donde se han desarrollado estas luchas. A los comunistas, socialistas, revolucionarios y demócratas que han dado estas batallas les debemos gran parte de las conquistas en derechos, libertades y justicia que ha alcanzado la humanidad.

A pesar de los intereses de los poderosos, los diálogos han avanzado, y esto significa que una nueva fase de la batalla de ideas y lucha política se abre. Batalla que se enriquecerá aún más con las otras dos fuerzas insurgentes, ELN y EPL, participando de los diálogos por la por la solución política del conflicto.

Por ejemplo, se ha avanzado en puntos concretos (hay 28 subpuntos de la agenda general que aún siguen sin resolverse en el congelador) [29], como en el primer punto de política de desarrollo agrario integral; en el de solución al problema de drogas ilícitas; en el de participación política; en el de las víctimas; en el nombramiento de la Comisión Histórica del Conflicto Armado que se encargará de presentar un informe sobre el origen histórico del conflicto, sus causas y actores.

No obstante, el peligro y las amenazas que aún corren los diálogos, se ha impuesto la voluntad popular movilizándose en defensa y apoyo al fin del conflicto y una paz con justicia social. Una señal del peligro que corren los diálogos, fue el caudal de votos y apoyo (más de 7 millones) con que aún cuenta la política de guerra del Uribismo y el Centro Democrático, las principales fuerzas que encabezan la oposición al proceso de diálogos y a la salida politica del conflicto armado, que cuentan con un sector de las Fuerzas Armadas, la Procuraduría y una permanente campaña sucia desde las redes sociales y algunos de los grandes medios de comunicación. 
Sin lugar a dudas la presión y oposición que sigue ejerciendo el sector de ultraderecha que encabeza el ex presidente Álvaro Uribe desde el Congreso, como fuerza política que se oponen al camino de la reconciliación y la solución politica, sigue siendo preocupante pero no necesariamente determinante. Es probable que esa tendencia política no esté en auge sino en declive, a pesar de contar con un apoyo amplio de sectores de la ciudadanía.

También hay enemigos del proceso de diálogos en dirigentes politicos regionales, conocidos por el apoyo y beneficio que obtuvieron del paramilitarismo. Son los parapolíticos que fueron condenados a irrisorias penas de prisión y muchos absueltos a pesar de comprobarse su relación con los ejércitos criminales.

Los responsables políticos e ideológicos del paramilitarismo en Colombia, siguen sin ser condenados y gozan de los beneficios y blindaje que les brinda un Estado y sus instituciones moldeadas y diseñadas para que no los condenara y juzgara por las grandes masacres y violaciones de derechos humanos que cometieron en alianza con las Fuerzas Armadas.

Sigue siendo una estrategia defendida por un puñado de neofascistas, fanáticos católicos, cristianos, liberales, conservadores, anticomunistas y sectores de las Fuerzas Armadas con la anuencia de una gran parte del establecimiento, que de no ser tomada en serio, podría convertirse en el palo en la rueda de los nuevos esfuerzos por concretar una solución política al largo conflicto armado en Colombia. ¿Qué implicaciones tiene esto para el inmediato y mediano futuro? ¿Qué la guerra no va seguir siendo más la continuación de la politica por otros medios? De ser cierto, estariamos asistiendo al renacimiento de la politica (en el entendido que se pueda seguir la disputa por el poder por medio de las ideas y las propuestas politicas). Y ello nos debe llevar a reflexionar sobre el nuevo mapa de poder y configuraciones politicas, donde los movimientos sociales tienen un rol importante que jugar como alternativa de poder. Aquí es de gran importancia preguntarse acerca del papel que les corresponde a las fuerzas y movimientos politicos que emergen a la par con este proceso, como Marcha Patriótica, el Frente Amplio por la Paz, la Cumbre agraria, el movimiento social urbano, el juvenil y estudiantil, el campesino, el indigena, el nuevo movimiento sindical clasista, el afrodescendiente, las organizaciones de mujeres y otros.

La posibilidad de un acuerdo concreto que ponga fin al histórico enfrentamiento armado debe ser la principal prioridad de todas las fuerzas politicas, movimientos políticos y sociales de carácter populares. La pregunta que surge es ¿bajo qué condiciones y garantías reales de verificación podemos decirle adiós definitivamente a la confrontación armada en Colombia? ¿Por medio de un referendo que no ha sido acordado con las FARC, o por medio de una Asamblea Nacional Constituyente? ¿Qué significaría en la realidad y praxis de los movimientos sociales y políticos, partidos de oposición y de izquierda, el inicio de la llamada fase tres (fin del conflicto armado) del proceso? ¿Qué implicaría para la izquierda y los sectores democráticos que la guerrilla encontrara las condiciones para la lucha politica sin el recurso de las armas? ¿Estamos preparados para tan gigantesco salto cualitativo en la lucha politica? ¿Cómo abocar la tarea de la reconstrucción y articulación del sujeto histórico popular, para el cambio? Como vemos, no son pequeños, ni pocos los retos por delante. 


\section{Referencias Bibliográficas.}

2Orillas. (3 de Noviembre de 2013). Cuando las Farc intentaron hacer politica hace 29 años. Obtenido de las2orillas.co: http:/ / www.las2orillas.co/cuando-las-farcintentaron-hacer-politica/

Bolivar, S. (1812). Manifiesto de Cartagena. Obtenido de tss.gob.ve: http://www. tss.gob.ve/documents / 101455/0/Manifiesto+de+Cartagena.pdf

Bolivar, S. (1813). Decreto de Guerra a muerte. . Obtenido de rodrigomorenog. files.wordpress.com/: http://rodrigomorenog.files.wordpress.com/2012/01/ bolc3advar-decreto-guerra-a-muerte-1813.pdf

Bolivar, S., \& Morillo, P. (26 de Noviembre de 1820). Tratado de Armisticio. Obtenido de efemeridesvenezolanas.com: http://www.efemeridesvenezolanas.com/sec/ his/id/72/?show=1

Caracol Radio. (10 de Febrero de 2008). El gobierno descalifica la marcha del 6 de marzo. Recuperado el 24 de Agosto de 2014, de Caracol Radio: http://www. caracol.com.co/noticias / actualidad/el-gobierno-descalifica-la-marcha-del-6de-marzo/20080210/nota/546604.aspx

Centro de Memoria Histórica. (2013). Basta Ya Colombia: Memorias de guerra y dignidad. Bogotá: Centro de Memoria Histórica.

Conmocion en Colombia. (17 de Mayo de 2000). Recuperado el 30 de Octubre de 2013, de La Nación: http://www.lanacion.com.ar/17135-conmocion-en-colombia

El Pais. (2 de Marzo de 2008). La muerte de 'Raúl Reyes' desencadena una crisis diplomática entre Colombia, Venezuela y Ecuador. Obtenido de internacional. elpais.com:http:/ / internacional.elpais.com/internacional/2008/03/02/ actualidad/1204412408_850215.html

El Tiempo. (17 de Mayo de 2000). Barbarie de la Farc en Simijaca. Obtenido de El Tiempo: http://www.eltiempo.com/archivo/documento/MAM-1258999

El tiempo. (24 de Septiembre de 2002). Collar bomba, un solo condenado. Recuperado el 30 de Octubre de 2013, de El Tiempo: http://www.eltiempo.com/archivo/ documento/MAM-1333136

El Tiempo. (1 de Febrero de 2008). Familias prefieren vigilia a marcha. Recuperado el 24 de Agosto de 2013, de El Tiempo: http://www.eltiempo.com/archivo/ documento/MAM-2812248

El Tiempo. (17 de Enero de 2008). Indignación contra el secuestro moviliza a los colombianos. Recuperado el 24 de Agosto de 2014, de El Tiempo: http://www. eltiempo.com/archivo/documento/CMS-3924445 
El Tiempo. (31 de Enero de 2008). La marcha del 4 de febrero contra las Farc nació como un foro en Internet y ya está en 163 ciudades. Recuperado el 24 de Agosto de 2014, de El Tiempo: http://www.eltiempo.com/archivo/documento/CMS3941050

Farc-Ep. (2000). Fuerzas Armadas Revolucionarias de Colombia. Recuperado el 24 de Agosto de 2014, de farcpaz-ep.org: http://www.pazfarc-ep.org/

Fukuyama, F. (1992). El fin de la Historia. Obtenido de http://firgoa.usc.es/: http: / / firgoa.usc.es / drupal / files / Francis\%20Fukuyama\%20-\%20Fin\%20 de\%20la\%20historia\%20y\%20otros\%20escritos.pdf

García, A. (1977). Colombia: esquema de una república señorial. Bogotá: Cruz del Sur.

Herman, E., \& Shomsky, N. (2008). Manufacturing Consent: The Political Economy of the Mass Media. London: The Randon Haouse group limited.

Insuasty Rodriguez, A., \& Vallejo Duque, Y. (2012). Crar Ambiente para la Paz. Kavilando, 11-18.

Insuasty Rodriguez, A., Grisales Grajales, D., \& Gutierrez Leon, E. M. (30 de Diciembre de 2013). Conflictos asociados a la gran mineria en Antioquia. El Agora USB, 13(2), 371-397. Obtenido de http://web.usbmed.edu.co/usbmed/ elagora/htm/v13nro2/pdf/CONFLICTOS-ASOCIADOS-A-LA-GRAN-MINERIA. pdf

Insusty Rodriguez, A., \& Vallejo Duque, Y. (2008). Acción social ¿una dinámica para el desarrollo social o una estrategia para el control territorial? El Agora USB, 101-122.

López, T. (24 de Septiembre de 2014). Los puntos pendientes de la negociación. Recuperado el 10 de Octubre de 2014, de Las2Orilas: http://www.las2orillas. co/la-verdad-lo-que-esta-ocurriendo-en-la-mesa-de-la-habana/

Pnud. (2011). Colombia Rural. Razones para la esperanza. Recuperado el 24 de Agosto de 2014, de planipolis.iiep.unesco.org/: http://planipolis.iiep.unesco. org/upload/Colombia/Colombia_NHDR_2011_resumen.pdf

Romero, R. (2 de Febrero de 2013). ¿Los acuerdos de la Habana llevarán a una nueva constituyente? Obtenido de Rebelión: http://www.rebelion.org/noticia. php?id=158207

Semana. (9 de Septiembre de 2012). Diálogos Gobierno-FARC: arrancó lo duro. Obtenido de Revista Semana: http://www.semana.com/nacion/articulo/ dialogos-gobierno-farc-arranco-duro/264424-3

Silva Lujan, G. (1989). Nueva historia de Colombia Tomo II Historia, politica 19461986. Bogotá: Planeta Colombia Editorial S.A. 
Texto del acuerdo de Ralito. (17 de Enero de 2007). Obtenido de Revista Semana: http:/ / www.semana.com/on-line/articulo/texto-del-acuerdo-ralito/83002-3

Tovar Zambrano, B., \& Bejarano, J. A. (1989). Nueva Historia de Colombia Tomo V Economía, Café Industrial. Bogotá: Planeta Colombia Editorial.

Uribe, M. T. (5 de Diciembre de 2013). La masacre de las bananeras. Obtenido de Prensa Rural: http://prensarural.org/spip/spip.php?article1726

Vanguardia Liberal. (13 de Marzo de 2013). Este proceso es un reconocimiento a mi gobierno: Pastrana. Obtenido de vanguardia.com: http:/ /www.vanguardia.com/ actualidad/colombia/199354-este-proceso-de-paz-es-un-reconocimiento-a-migobierno

Wikipedia. (4 de Febrero de 2008). Un Millón de voces contra las Farc. Obtenido de Wikipedia: http://es.wikipedia.org/wiki/Un_mill\%C3\%B3n_de_voces_contra_ las_FARC

Zambrano, A. (18 de Octubre de 2012). Los discursos de la instalación de la Mesa de Diálogos. Recuperado el 2 de Agosto de 2014, de Razón Pública: http:/ /www. razonpublica.com/index.php/26-temas/recomendados/3348-los-discursos-dela-instalacion-de-la-mesa-de-dialogos.html 